\title{
Knee osteoarthritis severity concerning neutrophil-lymphocyte ratio
}

\author{
Auday Hussain Hassan Al-Janaby* \\ Orthopedic Department, Al-Zahrawi Hospital, Misan Health Directorate, Ministry of Health/Environment, Misan, Iraq.
}

Magna Scientia Advanced Research and Reviews, 2021, 02(02), 080-084

Publication history: Received on 20 June 2021; revised on 25 July 2021; accepted on 27 July 2021

Article DOI: https://doi.org/10.30574/msarr.2021.2.2.0054

\begin{abstract}
Osteoarthritis $(\mathrm{OA})$ is a disease with a significant inflammatory component. Neutrophil-lymphocyte ratio (NLR) level is a marker to determine inflammation. The study aimed to evaluate the association between the severity of knee $\mathrm{OA}$ and NLR. A case-control study was conducted in Al-Zahrawi from June 2017 to June 2018. A total of 100 knees OA were recruited and 50 healthy subjects as a control group. NLR was significantly higher in knee OA than controls, the mean value was (2.19 \pm 0.72$)$ and (1.97 \pm 0.88$)$, respectively. Older age, chronic pain, prolong the onset of diagnosis and high NLR were significantly associated with severe OA. Knee OA had higher NLR compared to healthy people. Higher NLR is associated with the severity of knee $\mathrm{OA}$ and it is a poor indicator.
\end{abstract}

Keywords: Neutrophil-lymphocyte ratio; Osteoarthritis; Bone sclerosis; Osteophytes

\section{Introduction}

Osteoarthritis (OA) is the most common form of arthritis, and it is a leading musculoskeletal cause of disability in elderly persons [1]. OA is a chronic multifactorial disease with progressive joint degeneration accompanied by sub-chondral bone sclerosis, bone cysts formation, marginal osteophytes, knee flexibility decrease, arthralgia, joint effusion, crepitus, and deformities [2]. It is likely to increase due to aging and obesity [3]. The diagnosis confirms by history, physical examination, imaging studies, and laboratory testing [4]. X-rays reveal marginal osteophytes, narrowing of the space, increased density of the subchondral bone, subchondral cyst formation, bony remodeling, and joint effusions [5]. NLR is the ratio between the absolute neutrophil and lymphocyte counts [6-8].

\section{Methods}

\subsection{Study design and Setting}

This was a case-control study conducted in Al-Zahrawi from June 2017 to June 2018. A total of 100 knees OA were recruited and 50 healthy subjects as a control group.

\subsection{Participants}

A total of 100 patients with OA according to the American College of Rheumatology clinical criteria [9], attended the outpatient clinic. A total of 50 healthy subjects agreed to participate in the study.

\subsection{Exclusion criteria}

- History of knee trauma.

\footnotetext{
${ }^{*}$ Corresponding author: Auday Hussain Hassan Al-Janaby

Orthopedic Department, Al-Zahrawi Hospital, Misan Health Directorate, Ministry of Health/Environment, Misan, Iraq. 
- Post-infection arthropathy.

- Tumor.

- Rheumatoid arthritis.

- $\quad$ Systemic lupus erythematosus (SLE).

\subsection{Data collection}

Data were collected including age, gender, BMI, smoking, drug history, and medical history. The clinical and laboratory data including the radiological findings and NLR. The OA grade was assessed according to the Kellgren-Lawrence (KL) grading system [10].

\subsection{Statistical analysis}

Data entered and analyzed using the statistical package for social sciences (SPSS) version 24. Descriptive statistics presented as frequencies, percentage (\%), mean and standard deviation. Analytic statistics performed using Chi-square to compare frequencies for student's t-test and ANOVA test was used to compare means. The level of significance was set at $<0.05$.

\section{Results}

There were no statistically significant differences had been found between the groups in demographic variables, (Table 1). The value of NLR; patients with OA had significantly higher NLR than controls, the mean NLR was (3.02 \pm 0.87$)$ and (1.86 \pm 0.9$)$, respectively, $(\mathrm{P}=0.001)$, (Table 2). Regarding the distribution of the knee OA patients according to their KL grading scale, (18\%) grade I, (32\%) grade II, (21\%) grade III, and (29\%) grade IV, (Table 3). Regarding the severity, among these variables, age, and NLR were significantly different, (Table 4).

Table 1 Demographic of the studied groups

\begin{tabular}{|l|l|c|c|c|c|c|}
\hline \multicolumn{2}{|c|}{} & \multicolumn{2}{|l|}{ OA (No.= 100) } & \multicolumn{2}{l|}{ Control (No. = 50) } & \multirow{2}{*}{ P-value } \\
\cline { 2 - 6 } \multicolumn{2}{|c|}{} & No. & \% & No. & \% & \\
\hline \multirow{2}{*}{ Age (year) } & Mean \pm SD & $60.4 \pm 8.9$ & - & $62.3 \pm 8.1$ & - & 0.09 \\
\hline \multirow{3}{*}{ Gender } & Male & 35 & 35 & 25 & 50 & \multirow{2}{*}{0.077} \\
\cline { 2 - 6 } & Female & 65 & 65 & 25 & 50 & \\
\hline \multirow{2}{*}{ Smoking } & Yes & 77 & 77 & 30 & 30 & \multirow{2}{*}{0.069} \\
\cline { 2 - 6 } & No & 23 & 23 & 20 & 20 & \\
\hline \multirow{2}{*}{ BMI } & Mean \pm SD & $29.1 \pm 4.3$ & - & $28.8 \pm 3.7$ & - & 0.49 \\
\hline
\end{tabular}

Table 2 NLR of the studied groups

\begin{tabular}{|c|c|c|c|}
\hline & OA (No.= 100) & Control (No.= 50) & P-value \\
\hline NLR & $3.02 \pm 0.87$ & $1.86 \pm 0.9$ & 0.001 \\
\hline
\end{tabular}

Table 3 Osteoarthritis patients according to the Kellgren-Lawrrence grading system

\begin{tabular}{|c|c|c|}
\hline Grade & No. & \% \\
\hline I & 18 & 18 \\
\hline II & 32 & 32 \\
\hline III & 21 & 21 \\
\hline IV & 29 & 29 \\
\hline Total & 100 & \\
\hline
\end{tabular}


Table 4 Association of age and NLR with the severity of OA

\begin{tabular}{|l|c|c|c|c|}
\hline Variable & $\begin{array}{l}\text { Mild } \\
\text { (No.= 18) }\end{array}$ & $\begin{array}{l}\text { Moderate } \\
\text { (No.= 53) }\end{array}$ & $\begin{array}{l}\text { Severe } \\
\text { (No.= 29) }\end{array}$ & P-value \\
\hline Age (year) & $60.1 \pm 8.2$ & $62.4 \pm 7.7$ & $64.1 \pm 9.1$ & 0.001 \\
\hline NLR & $2.76 \pm 0.55$ & $3.11 \pm 0.6$ & $3.81 \pm 1.21$ & 0.01 \\
\hline
\end{tabular}

\section{Discussion}

The demographic data are similar to the clinical picture of OA documented previously, where the majority of the patients were old age and female was the dominant gender [11, 12]. There are no statistically significant differences in all hematological parameters except NLR. Despite that, there were very few studies available about the association between NLR and OA. The findings were consistent with Tasoglu, et al. [13].

Recently, Hira and Tamam [14], reported the mean NLR was significantly higher in the OA group than in controls. There was inconsistency about the predictive role of NLR in diagnosis, prognosis, or as a marker for disease activity for other diseases [15-17].

The correlation between the severity of $\mathrm{OA}$ and the variables that showed significant association on univariate analysis, older age, and higher NLR was still significantly associated with severe OA. Previous studies mentioned that old age is a significant risk factor of $\mathrm{OA}$ and associated with severe $\mathrm{OA}[11-13,18]$. The explanation beyond could be attributed to the general incidence and prevalence of $\mathrm{OA}$ has been reported to increase by ten times in older age than younger, particularly $>65$ years who are commonly affected by OA. Also, there is a change in behavior, lifestyle, diet, and other factors. In addition, the cells and extracellular matrix of joint tissues increase the susceptibility of older adults to OA [18, 19].

\section{Conclusion}

Osteoarthritis had higher NLR compared to healthy subjects. NLR is a poor predictor of OS severity. Age was a stronger risk factor of severity.

\section{Compliance with ethical standards}

\section{Acknowledgments}

Authors wish to acknowledge Dr. Ahmed Alshewered for his helping.

\section{Disclosure of conflict of interest}

There was no conflict of interest to be declared.

\section{Statement of ethical approval}

Taken from Orthopedic Department, Al-Zahrawi Hospital committee.

\section{Statement of informed consent}

Informed consent was obtained from all individual participants included in the study.

\section{References}

[1] Jonsson H, Helgadottir GP, Aspelund T, et al. Hand osteoarthritis in older women is associated with carotid and coronary atherosclerosis: the AGES Reykjavik study. Annals of the rheumatic diseases. 2009; 68(11): 1696-700.

[2] Gupta KB, Duryea J, Weissman BN. Radiographic evaluation of osteoarthritis. Radiologic Clinics. 2004; 42(1): 1141.

[3] Zhang Y, Jordan JM. Epidemiology of osteoarthritis. Clinics in geriatric medicine. 2010; 26(3): 355-69. 
[4] Szebenyi B, Hollander AP, Dieppe P, et al. Associations between pain, function, and radiographic features in osteoarthritis of the knee. Arthritis \& Rheumatology. 2006; 54(1): 230-5.

[5] Hochberg MC, Altman RD, April KT, et al. American College of Rheumatology 2012 recommendations for the use of non-pharmacologic and pharmacologic therapies in osteoarthritis of the hand, hip, and knee. Arthritis care \& research. 2012; 64(4): 465-74.

[6] Uslu AU, Deveci K, Korkmaz S, et al. Is neutrophil/lymphocyte ratio associated with subclinical inflammation and amyloidosis in patients with familial Mediterranean fever? BioMed research international. 2013; (185317): 1-5

[7] Taşoğlu I, Çiçek OF, Lafcı G, et al. Usefulness of neutrophil/lymphocyte ratio as a predictor of amputation after embolectomy for acute limb ischemia. Annals of vascular surgery. 2014; 28(3): 606-13.

[8] Galizia G, Lieto E, Zamboli A, et al. Neutrophil to lymphocyte ratio is a strong predictor of tumor recurrence in early colon cancers: A propensity score-matched analysis. Surgery. 2015; 158(1): 112-20.

[9] Heidari B. Knee osteoarthritis prevalence, risk factors, pathogenesis, and features: Part I. Caspian journal of internal medicine. 2011; 2(2): 205.

[10] Kohn MD, Sassoon AA, Fernando ND. Classifications in Brief: Kellgren-Lawrence Classification of Osteoarthritis. Clin Orthop Relat Res. 2016; 474(8): 1886-1893.

[11] Dieppe P, Berenbaum F. Ostearthritis. In: John H, Leslie J, Patience H (eds) Primer on the Rheumatic Disease. $13^{\text {th }}$ edition. New York: USA, Springer Science and Business Media. 2008; (Appendix): 669-82.

[12] Silverwood V, Blagojevic-Bucknall M, Jinks C, et al. Current evidence on risk factors for knee osteoarthritis in older adults: a systematic review and meta-analysis. Osteoarthritis and cartilage. 2015; 23(4): 507-15.

[13] Taşoğlu Ö, Bölük H, Onat SS, Taşoğlu İ, Özgirgin N. Is blood neutrophil-lymphocyte ratio an independent predictor of knee osteoarthritis severity? Clinical rheumatology. 2016; 35(6): 1579-83.

[14] Hira S, Tamam C. Diagnostic value of hematological parameters in patients with osteoarthritis. Cukurova Med J. 2017; 42(1): 114-9.

[15] De Rezende MU, de Campos GC. Is osteoarthritis a mechanical or inflammatory disease? Revista Brasileira de Ortopedia (English Edition). 2013; 48(6): 471-4.

[16] Pelletier JP, Martel-Pelletier J, Abramson SB. Osteoarthritis, an inflammatory disease: potential implication for the selection of new therapeutic targets. Arthritis \& Rheumatology. 2001; 44(6): 1237-47.

[17] Aur M, Wang H-Y, Kraus VB, et al. Radiographic severity of knee osteoarthritis is conditional on interleukin 1 receptor antagonist gene variations. Ann Rheum Dis. 2010; 69(5): 856-61.

[18] Bhatia D, Bejarano T, Novo M. Current interventions in the management of knee osteoarthritis. Journal of pharmacy \& bioallied sciences. 2013; 5(1): 30.

[19] Anderson AS, Loeser RF. Why is osteoarthritis an age-related disease? Best Practice \& Research Clinical Rheumatology. 2010; 24(1): 15-26. 